Peltzer et al., Afr J Tradit Complement Altern Med. (2016) 13(3):95--100

http://dx.doi.org/10.4314/ajtcam.v13i3.12

\title{
TRADITIONAL, COMPLEMENTARY AND ALTERNATIVE MEDICINE USE IN A COMMUNITY POPULATION IN LAO PDR
}

\author{
Karl Peltzer ${ }^{1,2,3 *}$, Kongmany Sydara ${ }^{4}$, and Supa Pengpid ${ }^{1,2}$ \\ ${ }^{1}$ ASEAN Institute for Health Development, Mahidol University, Salaya, Phutthamonthon, \\ Nakhon Pathom 73170, Thailand ${ }^{2}$ Department of Research and Innovation, University of Limpopo, Sovenga \\ 0727, South Africa ${ }^{3}$ HIV/AIDS/STIs/and TB (HAST), Human Sciences Research Council, Pretoria 0001, \\ South Africa ${ }^{4}$ Institute of Traditional Medicine, Vientiane, Lao PDR \\ *Corresponding author: E-mail: karl.pel@mahidol.ac.th
}

\begin{abstract}
Background: The aim of this study was to assess the prevalence and associated factors of Traditional, Complementary and Alternative Medicine (TCAM) use in a community setting in a central province of Lao PDR.

Materials and Methods: A cross-sectional community survey in 4 urban and 4 rural districts was conducted with the International Complementary and Alternative Medicine Questionnaire (I-CAM-Q).

Results: Of the 1600 participants in the survey, the overall prevalence of any TCAM use (providers, products or self-care) was $40.2 \%$ (TCAM provider $=14.8 \%$, TCAM products $=34.1 \%$, and self-help TCAM $=4.5 \%$ ) in the past 12 months. The most frequently used herbal medicines were Maringa pterygosperma (12.6\%), followed by Curcuma longa L. (9.4\%), Curcuma xanthorrhiza (9.4\%) and Centella asiatica (7.2\%). Many of the TCAM products were used for the purpose of health tonic or nourishments and for a number of chronic conditions (gout, dyslipidaemia, hypertension, diabetes, asthma, cancer, migraine, mental disorder, and gastrointestinal disorders). In multivariate logistic regression, lower educational level, rural residence and having chronic conditions was associated with any TCAM use.

Conclusions: TCAM use seems to be common in Lao PDR and better knowledge on the use of different TCAM modalities in this population may improve patient management.
\end{abstract}

Key words: Complementary medicine, Traditional medicine, Utilization, Community setting, Lao PDR

\section{Introduction}

Harris et al. (2012) found in a review of the 12-month prevalence of Traditional, Complementary and Alternative Medicine (TCAM) use by general populations in predominantly high income countries estimates of $9.8 \%$ to $76 \%$ of any TCAM usage and $1.8 \%$ to $48.7 \%$ of visits to TCAM practitioners. Cooper et al. (2013) reviewed the use of five types of complementary and alternative medicine practitioners by the general population in high income countries, and found the prevalence of visits by adults were $7.5 \%$ chiropractors, $1.9 \%$ osteopaths, $1.5 \%$ homeopaths $1.4 \%$ acupuncturists and $0.9 \%$ medical herbalists. In a few population-based studies in Southeast Asian Association countries high proportions of TCAM use have been found. In a community survey ( $\mathrm{N}=600)$ in a Southern province in Lao PDR, Sydara et al. (2005) found that 77\% of households had ever used and 59\% had used traditional medicine in the past 6 months, including herbal medicines, sauna, massage and acupuncture. In a national survey in Malaysia, Siti et al. (2009) found the past 12 months prevalence of TCAM use was 56.6\%, while Aziz and Tey (2009) found in four urban Malaysian towns that the use of herbal medicines in the previous 12 months was 33.9\%. In Singapore, Lim et al. (2005) found in surveying a housing estate that TCAM use in past 12 months was 76\%. In Thailand, Tangkiatkumjai et al. (2014) found in a cross-sectional community survey of 400 Thai people aged 15 years or over in Bangkok that the prevalence of herbal and dietary supplements usage in the previous 6 months was 52\%. Major specific TCAM modalities used across the different local studies in Asian Association countries included vitamins/mineral supplements, herbal medicines, sauna, massage, acupuncture, aromatherapy, yoga, chiropractic medicine, and traditional dental treatment (Peltzer and Pengpid, 2015).

Factors associated with TCAM use in general population surveys include (1) sociodemographic variables, female gender (Aziz and Tey, 2009; Bishop and Lewith, 2008; Lim et al., 2005), being married (Aziz and Tey, 2009), having high-income levels (Aziz and Tey, 2009), lower educational level (Sydara et al., 2005), higher educational level, probably more likely in high income countries (Bishop and Lewith, 2008), rural residence (Stickley et al., 2013), and (2) health status, having health problems (Aziz and Tey, 2009), having more than one medical condition (Bishop and Lewith, 2008). TCAM usage in Singapore was to a large extent for the maintenance of health and to a lesser extent for treatment of acute illness (Lim et al. 2005), while in Lao PDR most (71\%) indicated that the reason for them to use traditional medicine was that it can cure (Sydara et al. 2005).

The Lao government supports the use of traditional medicine in the prevention and treatment of diseases among the Lao people and acknowledges the importance of medicinal plants and traditional medicine (Sydara et al. 2005). One reason for the heavy use of medicinal plants in Laos is the limited access to Western health care systems by the majority of the population who live in rural areas (Sydara et al. 2005). There is a lack of recent studies on TCAM utilization in the community in the Southeast Asian Association region, including Lao PDR.

The aim of this study was to conduct a cross-sectional survey on the prevalence and associated factors of TCAM use in a community setting in a central province of Lao PDR. 
Peltzer et al., Afr J Tradit Complement Altern Med. (2016) 13(3):95--100

http://dx.doi.org/10.4314/ajtcam.v3i3.12

\section{Materials and Methods}

Sample and Procedure

The sample size included at least 800 persons from four rural communities (districts) and 800 individuals from four urban communities (districts). The 4 rural and 4 urban study districts had been randomly selected from 9 districts in the central province. All of the districts were from Vientiane Capital; urban districts: 1. Sisattanak, 2. Chanthabouly, 3. Sikhottabong, 4. Xaysetha; rural districts: 1. Pak Ngeum, 2. Naxaythong, 3. Xaythany, 4. Hatxayfong. For the selection of 1600 households, we used a stratified twostage sampling procedure. From every selected household in the study communities one interviewee (18 years and above) was randomly selected. Participants were informed about the nature of this study prior to taking informed consent and proceeding with the interview. Trained research assistants conduct interviews with the community members at their homes, using structured questionnaires. The questionnaire was translated and back-translated by certified translators into the study language, Lao. The questionnaire was pre-tested for validity in a sample of community members, which did not form part of the final sample. The Committee on Research Ethics (Social Sciences) of Mahidol University (COA No.: 2014/193.0807), and the Ministry of Public Health, Lao PDR approved the study protocol.

\section{Measure}

The "International questionnaire to measure the use of complementary and alternative medicine" (I-CAM-Q) (Quandt et al., 2009) was used. The I-CAM-Q contains three sections. Section 1 asks about "Visiting health care providers", section 2 about the "Use of herbal medicine and dietary supplements" and section 3 about "Self-help practices" (Re et al., 2012). The different treatment modalities are presented in the form of a list, and participants can report on the different types of TCAM use in the past 12 months (yes/no) (Re et al., 2012). Participants are also asked if the particular TCAM therapy was used for an acute illness/condition, a longterm illness (one that lasted more than one month), to improve general well-being, or for other reasons (if necessary) (Re et al., 2012). Patients were also asked about the names of herbal and supplementary medicines they are using, their purpose and form of usage (Tangkiatkumjai et al., 2013). Finally, respondents are asked to indicate how helpful the TCAM treatments had been and the sources of TCAM information.

Health status questions included the receipt of treatment in the past 12 months for a number of chronic diseases, such as diabetes and migraine headaches.

\section{Data Analysis}

Frequencies, means, and standard deviations, were calculated to describe the sample. Stepwise backward conditional logistic regression was used with the independent variables of gender, age, education, geo-locality, and number of co-morbid medical conditions, and the dependent variable was any TCAM use in the past 12 months. P levels of $<0.05$ were considered significant. All statistical analyses are carried out using IBM (International Business Machines Corporation) SPSS (Statistical Package for the Social Sciences) version 22.

\section{Results}

\section{Sample Characteristics}

Overall, 1600 persons were approached and 1600 agreed to participate in the study (100\% response rate). The overall mean age of participants was 42.3 years ( $\mathrm{SD}=14.7), 54.9 \%$ were women, most $(72.8 \%$ ) had Grade 6 to 12 education, and half of participants resided in an urban and half in rural areas. Respondents had been treated in the past 12 months for stomach and intestinal disease (11.9\%), followed by hypertension (8.5\%), diabetes (4.4\%), dyslipidaemia (3.8\%) and gout and other musculoskeletal conditions (2.9\%) (see Table 1$)$.

Table 1: Sample characteristics

\begin{tabular}{lll}
\hline & $\mathrm{N}$ & $\%$ \\
\hline Sites & & \\
Urban districts & 800 & 50.0 \\
Sisattanak & 200 & 12.5 \\
Chanthabouly & 200 & 12.5 \\
Sikhottabong & 200 & 12.5 \\
Xaysetha & 200 & 12.5 \\
Rural districts & 800 & 50.0 \\
Pak Ngeum & 200 & 12.5 \\
Naxaythong & 200 & 12.5 \\
Xaythany & 200 & 12.5 \\
Hatxayfong & 200 & 12.5 \\
Age - Mean (SD) & 42.3 & 14.7 \\
Gender & & \\
Male & 722 & 45.1 \\
Female & 878 & 54.9 \\
Education & & \\
No formal education & 31 & 1.9 \\
Grade1-5 & 258 & 16.1 \\
Grade 6-12 & 1164 & 72.8 \\
\hline
\end{tabular}


Peltzer et al., Afr J Tradit Complement Altern Med. (2016) 13(3):95--100

http://dx.doi.org/10.4314/ajtcam.v3i3.12

\begin{tabular}{|c|c|c|c|}
\hline \multicolumn{2}{|c|}{ Postsecondary } & 147 & 9.2 \\
\hline \multicolumn{2}{|c|}{$\begin{array}{l}\text { Chronic conditions Treated in the past } 12 \text { months, for the following } \\
\text { conditions... }\end{array}$} & $\mathrm{N}$ & $\%$ \\
\hline 1) & Stomach and intestinal disease & 224 & 11.9 \\
\hline 2) & Hypertension & 136 & 8.5 \\
\hline 3) & Diabetes mellitus & 70 & 4.4 \\
\hline 4) & Dyslipidaemia & 61 & 3.8 \\
\hline 5) & Gout and other musculoskeletal conditions, such as chronic & 46 & 2.9 \\
\hline \multicolumn{4}{|c|}{ backache } \\
\hline 6) & Migraine or frequent headaches & 34 & 2.1 \\
\hline 7) & Arthritis & 28 & 2.0 \\
\hline 8) & Mental disorder & 26 & 2.0 \\
\hline 9) & Liver disease & 21 & 1.3 \\
\hline 10) & Kidney disease & 18 & 1.2 \\
\hline \multicolumn{4}{|c|}{ 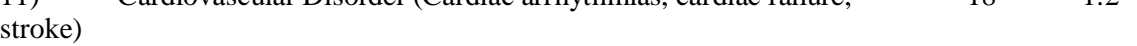 } \\
\hline 12) & Asthma & 14 & 0.9 \\
\hline 13) & Chronic obstructive pulmonary disease (COPD) & 7 & 0.4 \\
\hline 14) & Thyroid disease & 3 & 0.2 \\
\hline 15$)$ & Cancer & 2 & 0.1 \\
\hline \multicolumn{2}{|c|}{ Number of chronic conditions - Mean (SD) } & 0.5 & 0.7 \\
\hline
\end{tabular}

\section{Health Care Providers Consulted}

Table 2 shows the participants' utilization of various health care providers in the past 12 months. In all, $226(14.8 \%)$ had visited a TCAM provider in the past year, $11.2 \%$ one type and $3.6 \%$ two or more types. The TCAM providers most frequently consulted were the herbalist (7.5\%), massage therapist (5.4\%), and other alternative medicine provider (4.9\%). Participants consulted TCAM providers because of acute illness, long term illness and to improve well-being. For most TCAM providers (herbalist, acupuncturist, other alternative medicine provider, massage therapist) more than $70 \%$ of participants perceived the consultation as very or somewhat helpful, while the ratings were below $30 \%$ for the spiritual healer, chiropractor and yoga practitioner (see Table 2 ).

Table 2: Health care providers seen in the past 12 months

\begin{tabular}{|c|c|c|c|c|c|}
\hline \multirow{2}{*}{$\begin{array}{l}\text { Health care providers } \\
\text { consulted in the past } 12 \\
\text { months }\end{array}$} & \multirow{2}{*}{ Visited } & \multicolumn{3}{|c|}{ Motivation } & \multirow{2}{*}{$\begin{array}{l}\text { Helpfulness } \\
\text { Very/somewhat } \\
\% 1 \%\end{array}$} \\
\hline & & $\begin{array}{l}\text { Acute } \\
\text { illness } \\
\%\end{array}$ & $\begin{array}{l}\text { Long term } \\
\text { illness } \\
\%\end{array}$ & $\begin{array}{l}\text { To improve } \\
\text { well-being or } \\
\text { other } \%\end{array}$ & \\
\hline Medical practitioner & $750(51.4)$ & 47.8 & 23.9 & 28.3 & $58.4 / 22.8$ \\
\hline Herbalist & $116(7.5)$ & 47.1 & 47.1 & 5.9 & $59.1 / 40.9$ \\
\hline Spiritual healer & $18(1.2)$ & 90.0 & -- & 10.0 & $0.0 / 25.0$ \\
\hline $\begin{array}{l}\text { Other alternative } \\
\text { medicine provider }\end{array}$ & $78(4.9)$ & 71.6 & -- & 28.4 & $17.6 / 79.4$ \\
\hline Acupuncturist & $22(1.4)$ & 61.9 & 9.5 & 28.6 & $36.4 / 54.5$ \\
\hline Chiropractor & $31(1.9)$ & 78.1 & 9.4 & 12.5 & $9.6 / 9.6$ \\
\hline Yoga practitioner & $19(1.2)$ & 27.8 & 33.3 & 33.3 & $4.4 / 6.7$ \\
\hline Massage therapist & $87(5.4)$ & 53.1 & 3.7 & 43.2 & $49.2 / 37.7$ \\
\hline Other & $38(2.7)$ & -- & 50.0 & 50.0 & $0.0 / 50.0$ \\
\hline
\end{tabular}

\section{TCAM products and self-help TCAM}

The use of TCAM products (herbal medicine and supplements) in the past 12 months was the most commonly used TCAM modality, with 541 (34.1\%) of participants having utilized at least one type of TCAM in the past 12 months, $21.5 \%$ one type and $12.6 \%$ two or more types. The most frequently used TCAM products have been vitamins/minerals (35.1\%), followed by other supplements (22.3\%) and herbal medicine (21.3\%). In terms of self-help TCAM, 73 (4.5\%) had used self-help TCAM in the past 12 months, the most common being meditation $(6.2 \%)$, Yoga $(2.8 \%)$ and attended a traditional healing ceremony $(2.0 \%)$. The most commonly mentioned motivation for the use of TCAM products and self-help TCAM have been long term illness and to improve well-being. More than $80 \%$ of participants perceived the use of their different TCAM products and self-help TCAM as very or somewhat helpful (see Table 3). The prevalence of any TCAM use (providers, products or self-care) was $40.2 \%$.

Table 4 provides details about the most commonly used TCAM products (herbal and dietary supplements) in the past 12 months, the purpose of using it and how it was obtained. The most frequently used herbal medicines were Maringa pterygosperma (12.6\%), followed by Curcuma longa L. (9.4\%), Curcuma xanthorrhiza (9.4\%) and Centella asiatica (7.2\%). Many of the TCAM products were used for the purpose of health tonic or nourishments, and for a number of chronic conditions (gout, dyslipidaemia, hypertension, diabetes, asthma, cancer, migraine, mental disorder, and gastrointestinal disorders). Most frequently TCAM products had been obtained from folk remedy shops or stands, followed by direct sale, health food store, provided by family or friends, drug store and own garden (see Table 4). 
Peltzer et al., Afr J Tradit Complement Altern Med. (2016) 13(3):95--100

http://dx.doi.org/10.4314/ajtcam.v3i3.12

Table 3: Use of herbal medicine and dietary supplements, and self-help practices

\begin{tabular}{|c|c|c|c|c|c|}
\hline \multirow[t]{3}{*}{ TCAM modality } & \multirow{2}{*}{ Used } & \multicolumn{3}{|c|}{ Motivation } & \multirow{3}{*}{$\begin{array}{l}\text { Helpfulness } \\
\text { Very/ somewhat } \\
\%\end{array}$} \\
\hline & & Acute illness & $\begin{array}{l}\text { Long term } \\
\text { illness }\end{array}$ & $\begin{array}{l}\text { To improve } \\
\text { well-being or }\end{array}$ & \\
\hline & $\mathrm{N}(\%)$ & $\%$ & $\%$ & other \% & \\
\hline \multicolumn{6}{|c|}{ Use of herbal medicine and dietary supplements, including tablets, capsules and liquids } \\
\hline Herbs/herbal medicine & $283(21.3)$ & 21.7 & 16.4 & 55.3 & $69.3 / 28.4$ \\
\hline Vitamins/minerals & $534(35.1)$ & 37.7 & 26.4 & 35.1 & $88.3 / 11.7$ \\
\hline $\begin{array}{l}\text { Other alternative } \\
\text { medicines }\end{array}$ & $75(4.7)$ & 31.5 & 16.2 & 52.1 & $50.7 / 46.7$ \\
\hline Other supplements & $336(22.3)$ & 1.3 & 8.9 & 89.9 & $88.9 / 11.1$ \\
\hline \multicolumn{6}{|c|}{ Self-help practices } \\
\hline Meditation & $92(6.2)$ & - & 60.0 & 40.0 & $67.4 / 32.6$ \\
\hline Yoga & $38(2.8)$ & 10.0 & 40.0 & 50.0 & $76.8 / 23.1$ \\
\hline Relaxation techniques & $12(1.8)$ & 16.7 & 33.3 & 60.0 & $0 / 85.7$ \\
\hline $\begin{array}{l}\text { Attend traditional } \\
\text { healing ceremony }\end{array}$ & $21(2.0)$ & - & 50.0 & 50.0 & $10 / 80$ \\
\hline Prayer for own health & $19(1.6)$ & - & 44.4 & 55.6 & $80 / 20$ \\
\hline Other & $145(10.8)$ & - & 80.0 & 20.0 & $80 / 20$ \\
\hline
\end{tabular}

Table 4: Details of herbal and dietary supplements used

\begin{tabular}{|c|c|c|c|c|}
\hline $\begin{array}{l}\text { Local name of herbal } \\
\text { or dietary supplement }\end{array}$ & $\begin{array}{l}\text { Scientific name of herbal } \\
\text { or dietary supplement }\end{array}$ & $\mathrm{N}(\%)$ & Purpose of using it & How obtained\# \\
\hline Phak I Houm & Moringa pterygosperma & $35(12.6)$ & $\begin{array}{l}\text { Health tonic, mental disorder, gout, } \\
\text { dyslipidaemia, hypertension, diabetes }\end{array}$ & $2,6,7,3,5$ \\
\hline Khi min kheun & Curcuma longa $\mathrm{L}$. & $29(9.4)$ & Treatment; stomach & $2,1,6$ \\
\hline Van Hoa dio & $\begin{array}{l}\text { Curcuma xanthorrhiza } \\
\text { Robx }\end{array}$ & $26(9.4)$ & Health tonic, nourish body, asthma & $2,1,3,5,6$ \\
\hline Phak nok & Centella asiatica $\mathrm{L}$. & $20(7.2)$ & $\begin{array}{l}\text { Nourishment, health tonic, stomach; } \\
\text { detox }\end{array}$ & $6,7.8$ \\
\hline Hed Lin Cheu & Mushroom's Linchi & $17(6.1)$ & Health tonic, cancer & $3,6,2$ \\
\hline Mak Nhor Ban & Morinda citrifolia $\mathrm{L}$. & $14(5.1)$ & $\begin{array}{l}\text { Health tonic, nourishment, mental } \\
\text { disorder, stomach, hypertension }\end{array}$ & $2,5,6,3$ \\
\hline Mak Mai Pa Som & Fruit & $13(4.7)$ & Health tonic, nourishmentment & $5,6,1$ \\
\hline Nha Nuad Meo & $\begin{array}{l}\text { Orthosiphon stamineus } \\
\text { Benth. }\end{array}$ & $11(4.0)$ & $\begin{array}{l}\text { Kidney, hypertension, dyslipidaemia, } \\
\text { mental disorder }\end{array}$ & $2,3,5,6,7$ \\
\hline Khi Min Kheun & Curcuma longa $\mathrm{L}$. & $10(3.6)$ & Gastritis & 7 \\
\hline Som Kao Li & Ginseng & $9(3.2)$ & Health tonic, nourishment & $2,1,6,7$ \\
\hline Hang Nok & Aerodramus fuciphagus & $7(2.5)$ & Health tonic, nourishment & $2,3,1,5,7$ \\
\hline Dok An Xan & Clitoria ternatea $\mathrm{L}$. & $7(2.5)$ & Health tonic & 7,6 \\
\hline Phak Khao Thong & $\begin{array}{l}\text { Houttuynia cordata } \\
\text { Thumb }\end{array}$ & $7(2.5)$ & $\begin{array}{l}\text { Health tonic, nourishment, stomach, } \\
\text { migraine, allergy, aphthous ulcer, gout, } \\
\text { arthritis, hypertension }\end{array}$ & $8,2,1$ \\
\hline Adenosyl & Adenosma indianum (lour) & $6(2.2)$ & Treatment & 1 \\
\hline Mak Kham Pom & Phyllanthus embulica $\mathrm{L}$ & $6(2.2)$ & Health tonic, nourishment & $2,6,5$ \\
\hline Klo Ro Fil & Chlorophyll & $4(1.4)$ & Mental disorder, detox & 5,3 \\
\hline Phak Bua Leuat & $\begin{array}{l}\text { Eleutherine subaphylla } \\
\text { Gagnep }\end{array}$ & $4(1.4)$ & Stomach & 2,1 \\
\hline Omega 3 & Omega 3 & $4(1.4)$ & Health tonic & 5 \\
\hline $\mathrm{Ra} \mathrm{Xa} \mathrm{Bi}$ & $\begin{array}{l}\text { Andrographis panniculata } \\
\text { Wall }\end{array}$ & $3(1.1)$ & Health tonic & 8 \\
\hline Soup Kai Sa Kat & Soup's extract of chicken & $3(1.1)$ & Health tonic & 5,3 \\
\hline Van Hang Khe & Aloe vera $\mathrm{L}$. & $2(0.7)$ & $?$ & 7 \\
\hline Mak Mang Khout & Garcinia mangostna Linn & $2(0.7)$ & Diabetes, detox & 5 \\
\hline Collagen & Collagen & $2(0.7)$ & Health tonic & 5 \\
\hline None Nay & Desmodium triquetum $(\mathrm{L})$ & $2(0.7)$ & Health tonic & 8 \\
\hline Nha Nuat Meo & $\begin{array}{l}\text { Orthosiphon stamineus } \\
\text { Benth. }\end{array}$ & $2(0.7)$ & Kidney stone & 1 \\
\hline Kheua Leb Mau Nang & Scheffera ellitica Harms & $2(0.7)$ & Treatment & 6 \\
\hline
\end{tabular}

$\# 1=$ Drug store, $2=$ Folk remedy shop/stand, 3=Health food store, 4=Hospital, 5=Direct sale, 6=Provided by their family/ friends,

$7=$ Own garden, $8=$ Other

\section{Associations with Any TCAM Use}

In bivariate analysis, female gender, older age, no formal education, rural residence and having chronic conditions was associated with any TCAM use. In multivariate logistic regression, lower educational level, rural residence and having chronic conditions were associated with any TCAM use (see Table 5). 
Peltzer et al., Afr J Tradit Complement Altern Med. (2016) 13(3):95--100

http://dx.doi.org/10.4314/ajtcam.v3i3.12

Table 5: Associations between sociodemographic variables, chronic conditions and TCAM usage

\begin{tabular}{|c|c|c|c|c|}
\hline Variable & $\begin{array}{l}\text { Unadjusted Odds Ratio } \\
(95 \% \mathrm{CI})\end{array}$ & P-value & $\begin{array}{l}\text { Adjusted Odds Ratio } \\
(95 \% \mathrm{CI})^{\mathrm{a}, \mathrm{b}}\end{array}$ & P-value \\
\hline \multicolumn{5}{|c|}{$x_{1}$} \\
\hline Female & 1.00 & & -- & \\
\hline Male & $0.75(0.61-0.92)$ & $<0.001$ & & \\
\hline \multicolumn{5}{|l|}{ Age (in years) } \\
\hline $18-45$ & 1.00 & & -- & \\
\hline $46-60$ & $1.64(1.30-2.07)$ & $<0.001$ & & \\
\hline $61-101$ & $2.82(2.09-3.92)$ & $<0.001$ & & \\
\hline \multicolumn{5}{|l|}{ Education } \\
\hline No formal education & 1.00 & & 1.00 & \\
\hline Grade1-5 & $0.47(0.22-1.01)$ & 0.052 & & \\
\hline Grade 6-12 & $0.44(0.21-0.91)$ & 0.026 & & \\
\hline Postsecondary & $0.25(0.11-0.57)$ & 0.001 & $0.35(0.15-0.81)$ & 0.014 \\
\hline \multicolumn{5}{|l|}{ Geolocality } \\
\hline Rural & 1.00 & & 1.00 & \\
\hline Urban & $0.76(0.62-0.94)$ & 0.010 & $0.60(0.38-0.93)$ & 0.023 \\
\hline \multicolumn{5}{|l|}{ Chronic conditions } \\
\hline None & 1.00 & & 1.00 & \\
\hline One & $2.94(1.94-4.44)$ & $<0.001$ & $2.87(1.88-4.37)$ & $<0.001$ \\
\hline Two or more & $4.74(2.12-10.57)$ & $<0.001$ & $5.16(2.27-11.74)$ & $<0.001$ \\
\hline
\end{tabular}

$\mathrm{CI}=$ Confidence Interval; ${ }^{\mathrm{a}}$ Using stepwise backward conditional method

${ }^{\mathrm{b}}$ For Hosmer and Lemeshow Chi-square 6.00, df5, 0.306; Cox and Snell $\mathrm{R}^{2} 0.10$; Nagelkerke $\mathrm{R}^{2} 0.14$

\section{Discussion}

The study found an overall prevalence of any TCAM use (providers, products or self-care) of 40.2\% (TCAM provider= $14.8 \%$, TCAM products $=34.1 \%$, and self-help TCAM $=4.5 \%$ ) in the past 12 months, which seems to be lower than in an older community survey in Southern Lao PDR (59\% in the past 6 months) (Sydara et al., 2005), a national survey in Malaysia (Siti et al., 2009), a housing estate survey in Singapore (Lim et al., 2005) and a community survey in Bangkok, Thailand (Tangkiatkumjai et al., 2014). The most common TCAM providers found in this study were herbalist, other alternative medicine provider, acupuncturist, and massage therapist, which was similar to a previous community survey in southern Lao PDR (Sydara et al., 2005), and other community surveys in the region (Lim et al., 2005; Siti et al., 2009). This study found that TCAM utilization was higher in rural than in urban communities, which is in agreement with previous studies (e.g., Stickley et al., 2013). This finding may be explained by poorer access to and poorer quality of conventional health care services in rural areas (Wardle et al., 2012).

This study found that a high proportion of participants indicated that they use a TCAM provider and TCAM products for acute conditions. This finding may be similar to a previous study in Lao PDR (Sydara et al., 2005), with a high proportion of community members indicating the use of TCAM for conditions such as fever, diarrhoea, gastritis and malaria. In previous studies, Nonaka et al. (2009) and Sydara et al. (2005) report the common use of TCAM (faith healing and herbal remedy) for the treatment for malaria in Lao PDR. Likewise, a large proportion of dwellers in Bangkok took herbs to treat illnesses. TCAM self-help practices were in this study mainly used for long term health conditions and for improving well-being. Similarly, TCAM usage in Singapore was mainly for the maintenance of health (Lim et al., 2005).

Regarding sociodemographic associations with TCAM use, this study found, in agreement with previous studies (Aziz and Tey, 2009; Bishop and Lewith, 2008; Lim et al., 2005; Sydara et al., 2005), that female gender in bivariate analysis and lower educational level in multivariate analysis were associated with TCAM use. In terms of associations with health status, this study confirms previous research (Aziz and Tey, 2009; Bishop and Lewith, 2008), indicating that compared to TCAM non-users, TCAM users were more likely having one or more chronic diseases or conditions, especially mental, musculoskeletal and metabolic disorders (Nilsson et al., 2001; Peltzer and Pengpid, 2015). Mbada et al. (2015) also found in a community survey among rural farmers in Nigeria a high proportion of TCAM use (mainly herbal therapy and massage) for musculoskeletal pain.

\section{Study Limitations}

While the study was conducted in 4 rural and 4 urban districts in one province in Lao PDR, findings cannot be generalized to other provinces in Lao PDR. Further, there may have been a recall bias, given that study participants were retrospectively asked over the past 12 months about TCAM utilization.

\section{Conclusions}

The data indicate that TCAM use, in particular TCAM products such as herbal medicines, is common in Lao PDR. Several TCAM modalities and factors associated with TCAM use were identified which can be utilized for intervention programmes.

\section{Acknowledgement}

This project received support from Mahidol University, Thailand. 
Peltzer et al., Afr J Tradit Complement Altern Med. (2016) 13(3):95--100

http://dx.doi.org/10.4314/ajtcam.v3i3.12

\section{References}

1. Aziz, Z., and Tey, N.P. (2009). Herbal medicines: prevalence and predictors of use among Malaysian adults. Complement Ther Med, 17(1):44-50.

2. Bishop, F.L., and Lewith, G.T. (2010). Who uses CAM? A narrative review of demographic characteristics and health factors associated with CAM use. Evid Based Complement Alternat Med, 7(1):11-28.

3. Cooperm, K.L., Harris, P.E., Relton, C., and Thomas, K.J. (2013). Prevalence of visits to five types of complementary and alternative medicine practitioners by the general population: a systematic review. Complement Ther Clin Pract, 19(4):214-20.

4. Harris, P.E., Cooper, K.L., Relton, C., and Thomas, K.J. (2012). Prevalence of complementary and alternative medicine (CAM) use by the general population: a systematic review and update. Int J Clin Pract, 66(10):924-39.

5. Lim, M.K., Sadarangani, P., Chan, H.L., and Heng, J.Y. (2005). Complementary and alternative medicine use in multiracial Singapore. Complement Ther Med, 13(1):16-24.

6. Mbada, C.E., Adeyemi, T.L., Adedoyin, R.A., Badmus, H.D., Awotidebe, T.O., Arije, O.O., and Omotosho, O.S. (2015). Prevalence and modes of complementary and alternative medicine use among peasant farmers with musculoskeletal pain in a rural community in South-Western Nigeria. BMC Complement Altern Med. 5(1):164.

7. Nilsson, M., Trehn, G., and Asplund, K. (2001). Use of complementary andalternative medicine remedies in Sweden. A population-based longitudinal study within the northern Sweden MONICA Project. J Intern Med, 250(3): 225-233.

8. Nonaka, D., Vongseththa, K., Kobayashi, J., Bounyadeth, S., Kano, S., Phompida, S., and Jimba, M. (2009). Public and private sector treatment of malaria in Lao PDR. Acta Trop, 112(3):283-7.

9. Peltzer, K. and Pengpid, S. (2015). Utilization and practice of Traditional/Complementary/ Alternative Medicine (T/CAM) in Southeast Asian Nations (ASEAN) Member States. Stud Ethno-Med, 9(2): 209-218.

10. Quandt, S.A., Verhoef, M.J., Arcury, T.A., Lewith, G.T., Steinsbekk, A., Kristoffersen, A.E., Wahner-Roedler, D.L., and Fønneb $\varnothing$, V. (2009). Development of an international questionnaire to measure use of complementary and alternative medicine (I-CAM-Q). J Altern Complement Med, 15(4):331-9.

11. Re, M.L., Schmidt, S., and Güthlin, C. (2012). Translation and adaptation of an internationalquestionnaire to measure usage of complementary and alternative medicine (I-CAM-G). BMC Complement Altern Med, 12:259.

12. Siti, Z.M., Tahir, A., Farah, A.I., Fazlin, S.M., Sondi, S., Azman, A.H., Maimunah, A.H., Haniza, M.A., Siti Haslinda, M.D., Zulkarnain, A.K., Zakiah, I., and Zaleha, W.C. (2009). Use of traditional and complementary medicine in Malaysia: a baseline study. Complement Ther Med, 17(5-6):292-9.

13. Stickley, A., Koyanagi, A., Richardson, E., Roberts, B., Balabanova, D., and McKee, M. (2013). Prevalence and factors associated with the use of alternative (folk) medicine practitioners in 8 countries of the former Soviet Union. BMC Complement Altern Med, 13:83.

14. Sydara, K., Gneunphonsavath, S., Wahlström, R., Freudenthal, S., Houamboun, K., Tomson, G., and Falkenberg, T. (2005). Use of traditional medicine in Lao PDR. Complement Ther Med, 13(3):199-205.

15. Tangkiatkumjai, M., Boardman, H., Praditpornsilpa, K., and Walker, D.M. (2013). Prevalence of herbal and dietary supplement usage in Thai outpatients with chronic kidney disease: a cross-sectional survey. BMC Complement Altern Med, 13:153.

16. Tangkiatkumjai, M., Boardman, H., and Walker, D.M. (2014). Herbal and dietary supplement use in Bangkok: a survey. J Complement Integr Med, 11(3):203-11.

17. Wardle, J., Lui, C.W., and Adams, J. (2012). Complementary and alternative medicine in rural communities: current research and future directions. J Rural Health, 28(1):101-12. 